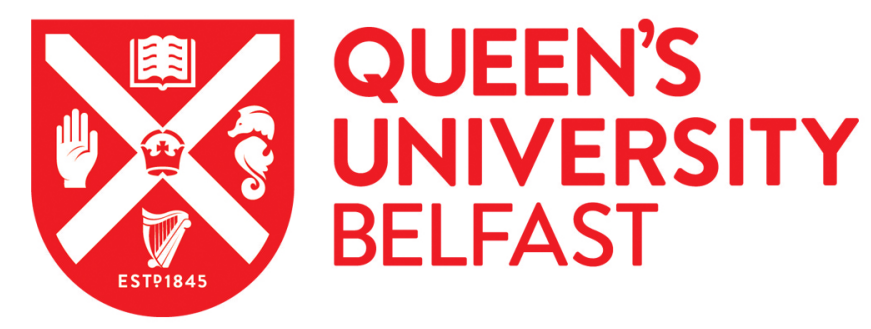

\title{
Hydrodynamic cavitation using vortex diode: An efficient approach for elimination of pathogenic bacteria from water
}

Jain, P., Bhandari, V. M., Balapure, K., Jena, J., Ranade, V. V., \& Killedar, D. J. (2019). Hydrodynamic cavitation using vortex diode: An efficient approach for elimination of pathogenic bacteria from water. Journal of Environmental Management, 242, 210-219. https://doi.org/10.1016/j.jenvman.2019.04.057

Published in:

Journal of Environmental Management

Document Version:

Peer reviewed version

Queen's University Belfast - Research Portal:

Link to publication record in Queen's University Belfast Research Portal

Publisher rights

Copyright 2019 Elsevier Ltd.

This manuscript is distributed under a Creative Commons Attribution-NonCommercial-NoDerivs License

(https://creativecommons.org/licenses/by-nc-nd/4.0/), which permits distribution and reproduction for non-commercial purposes, provided the author and source are cited.

\section{General rights}

Copyright for the publications made accessible via the Queen's University Belfast Research Portal is retained by the author(s) and / or other copyright owners and it is a condition of accessing these publications that users recognise and abide by the legal requirements associated with these rights.

Take down policy

The Research Portal is Queen's institutional repository that provides access to Queen's research output. Every effort has been made to ensure that content in the Research Portal does not infringe any person's rights, or applicable UK laws. If you discover content in the Research Portal that you believe breaches copyright or violates any law, please contact openaccess@qub.ac.uk. 


\title{
Hydrodynamic Cavitation using Vortex Diode: An Efficient Approach for Elimination of Pathogenic Bacteria from Water
}

\author{
Pooja Jain ${ }^{1,3}$, Vinay M. Bhandari ${ }^{1 *}$, Kshama Balapure ${ }^{1}$, Jyotsnarani Jena ${ }^{1}$, Vivek V. \\ Ranade $^{2}$, and Deepak J. Killedar ${ }^{3}$
}

\author{
${ }^{1}$ Chemical Engineering and Process Development Division, CSIR-National Chemical \\ Laboratory, Pune, India \\ ${ }^{2}$ School of Chemistry and Chemical Engineering, Queen's University Belfast, Northern Ireland, \\ UK
}

${ }^{3}$ Civil Engineering and Applied Mechanics Department. Shri. G.S. Institute of Technology and Science, Indore, India

\begin{abstract}
The present study successfully demonstrates greener methodology of hydrodynamic cavitation using rotational flows for disinfection of water. Disinfection of two model microbial strainsgram- negative (Escherichia coli) and gram- positive (Staphylococcus aureus) using vortex diode was evaluated. The removal efficacy was quantified for two different cavitation reactors. Practically complete elimination of $E$. coli was achieved $(99 \%)$ after $1 \mathrm{~h}$ of cavitation at a pressure drop of only 0.5 bar. However, elimination of $S$. aureus using vortex diode was observed to be lower in comparison to the removal of $E$. coli and only $60 \%$ disinfection could be achieved under similar conditions, which can be subsequently enhanced up to $98 \%$ by increasing pressure drop. The results were compared with another cavitating device that employs linear flow for cavitation, orifice. The reactor geometry has significant impact on the disinfection process and orifice was found to require significantly higher pressure drop (10 bar) conditions for disinfection and for eliminating gram- positive bacteria with high efficiency. A plausible mechanism for disinfection was proposed to elucidate the role of cavitation in cell destruction leading to death of cells through the rupture of cell wall, oxidative damage and possible DNA denaturation. Also, a cavitation model using per pass disinfection was developed that can provide meaningful physical description of the disinfection process as against the conventional first order reaction rate model. This study would provide meaningful insight into cavitation process based on hydrodynamic cavitation for the destruction of both gram- negative and gram- positive bacteria from various water sources, including industrial wastewaters.
\end{abstract}

Key words: Disinfection, Wastewater treatment, Pollution, Cavitation, Kinetics

\footnotetext{
${ }^{*}$ Corresponding author

E-mail: vm.bhandari@ncl.res.in

Tel: (+91) 2025902171; Fax: (+91) 2025893041
} 


\section{Introduction}

Disinfection of water is essential for removing pathogenic microorganisms that are responsible for causing a number of water borne diseases in the human society. Water quality is one of the most closely watched parameters worldwide to measure the standard of human life. Contaminated water can transmit a wide range of fatal diseases to human beings as well as to animals (Zou and Wang, 2017). The important prevalent waterborne diseases are typhoid, dysentery, cholera, infectious hepatitis and so on. According to the World Bank data, $88 \%$ of diseases in the developing world are caused by unsafe drinking water (Fogden, 2009). Due to water scarcity in many parts of the world and especially in India, possible recycling and reuse of wastewaters- sewage or industrial wastewater, after proper treatment, has become imperative, further highlighting the importance of the water disinfection (Ranade and Bhandari, 2014). Thus, it is essential to effectively remove, deactivate or kill the pathogenic microorganisms using techno-economically feasible methodologies.

Both, physical and chemical methods such as filtration, adsorption, coagulation and oxidation can be employed for achieving disinfection (Gogate, 2007). Typically, physical methods are based on the light (UV treatment), radiation or heat treatment, while the chemical methods demand addition of external disinfecting agent such as chlorine. The conventional and most widely practiced methods include, chlorination, ozonation and ultraviolet (UV) irradiation for water disinfection (Richardson et al., 2007; EPA, 2012). However, chlorination and ozonation are recently considered as not environment friendly; chlorination results in the formation of trihalomethanes (THM's) and other halogenated hydrocarbons, disinfection by-products having carcinogenic effects (Villanueva et al., 2015). Some microbial species produce bacterial colonies and spores that agglomerate in spherical or large cluster. Chemical treatment of such cluster only destroys the surface layer and the innermost part remains intact; consequently, complete cell destruction is not observed (Gogate, 2007). Further, the common physical techniques, such as UV irradiation, also have limitations of inadequate light scattering ability and inefficient when organisms have photoreactivation repair mechanism (Liang et al., 2013). An efficient disinfection methodology demands inactivation or destruction of the microorganism by destroying their cellular structure or disrupting the metabolism/ biosynthesis (Kirti et al., $\left.2018^{a, b}\right)$. Thus, judicious combination of existing methods or developing newer hybrid methodologies is essential and it is imperative to evaluate newer treatment methodologies that are effective, do not produce harmful byproducts, easy to operate and are also economical.

Cavitation can be one alternative in providing economical solution to water and wastewater treatment through destruction of various pollutants (Ranade and Bhandari, 2014) and is an excellent candidate as a hybrid process for replacing or integrating with existing chemical 
treatments (Badve et al., 2015; Zou and Wang, 2017; Čehovin et al., 2017). Cavitation is an easy to employ variant of oxidation process and generates oxidizing agents such as hydroxyl radicals through formation, growth and implosion of the cavities that results in the disinfection of the water/wastewaters. Jyoti and Pandit, (2001) reported use of hydrodynamic cavitation without specific cavitating device for disinfection of bore well water and also compared it with acoustic cavitation. In any cavitation process, oxidizing species such as $\mathrm{HO}$ are the most predominant radicals that are responsible for destruction of pollutants through oxidation and this was also observed for photocatalytic degradation of bacteria using $\mathrm{Cu}$-doped $\mathrm{TiO}_{2}$ (Karunakaran et al., 2011). Recently, Suryawanshi et al. (2017b) reported use of the hydrodynamic cavitation for the destruction of various organic pollutants.

Several studies have reported decontamination of water using hydrodynamic cavitation. However, design of cavitation and scale-up issues are yet to be satisfactorily resolved for improving techno-economic feasibility (Gogate, 2007). Moreover, cavitation based products/process have not yet received wide acceptance commercially for decontamination of water (Broekman et al., 2010). The intensification of cavitational activity largely depends on efficient design of the cavitation reactors which will address the cost issue as well as the efficiency (Bilek and Turantas, 2013). Hydrodynamic cavitation reactors are devices, typically without any moving parts, that employ linear flow or vortex flow for generating cavitation as against acoustic cavitation where ultrasound waves are used for generating cavitation. The common examples of hydrodynamic cavitation reactors include orifice, venturi and vortex diode etc. Cavitation with other chemical and biological methods was also reported to enhance microbial inactivation and elimination, and also its combination with other conventional chemical methods using chlorine, chlorine dioxide, acidified sodium chloride, organic acid formulations, alkaline-based sanitizers, hydrogen peroxide (Alexandre et al., 2013). The combination of electrolysis and ultrasound treatment was reported as an efficient method for the removal of Klebsiella pneumonia from water, the treatment efficiently reduced the current requirement (150 to $100 \mathrm{~mA}$ ) and treatment time (<10 $\mathrm{min}$ ) (Joyce et al., 2003). Čehovin et al. (2017) have reported different combinations such as $\mathrm{O}_{3}, \mathrm{H}_{2} \mathrm{O}_{2} / \mathrm{O}_{3}, \mathrm{H}_{2} \mathrm{O}_{2} / \mathrm{UV}$ and $\mathrm{O}_{3} / \mathrm{UV}$ with and without hydrodynamic cavitation for removal of organic matter from drinking water and found that combined treatment with cavitation employing orifice improves the process efficiency.

The present work is an attempt to provide an evaluation of two different cavitation reactors, orifice and vortex diode for the destruction of both gram- positive (Staphylococcus aureus) and gram- negative (Escherichia coli) bacteria. The two model organisms chosen for the disinfection study include enteric pathogens Escherichia coli and Staphylococcus aureus as these are the dominant species causing several types of water borne infections. A contaminated water sample was also evaluated for disinfection of pathogenic microorganisms for comparing the 
efficacy of the technique as against model/synthetic wastewater. The experimental investigations along with the developed mathematical model are expected to provide useful insight into the destruction of both gram- negative and gram- positive bacteria from water and waste waters with positive implications for possible commercial applications in the form of greener technology.

\section{Materials and Methods}

Escherichia coli (ATCC-8739) and Staphylococcus aureus (ATCC-6538) were obtained from National Collection of Industrial Microorganism (NCIM), CSIR-NCL, Pune. For preparation of model contaminated water, a loop of the bacterial colony was inoculated into $20 \mathrm{ml}$ Nutrient Broth (Himedia Nutrient HiVeg broth), incubated at $37^{\circ} \mathrm{C}$ overnight in incubator-shaker (200 $\mathrm{rpm}$ ). The known concentration of overnight grown bacterial cultures were added to the $12 \mathrm{~L}$ of distilled water to obtain a total bacterial concentration approximately $10^{3}$ colony forming units $(\mathrm{CFU}) / \mathrm{ml}$ of $E$. coli and S. aureus. Apart from model contaminated water system containing known microorganism of predetermined concentration, a contaminated water sample collected locally from an intermediate storage tank, with mix of various unidentified microorganisms was also used to evaluate efficacy of the treatment method.

\section{Experimental}

The disinfection process using hydrodynamic cavitation was carried out by pumping wastewater stream of known initial bacterial concentration under ambient conditions through the cavitating device such as orifice or vortex diode (nominal rated capacity, $1 \mathrm{~m}^{3} / \mathrm{h}$ ) at predefined pressure drop conditions. The conventional method to get overnight grown culture for the experiment was adopted (Loraine et al., 2012, Mezule et al., 2009). Here, incubation that continues till midpoint of exponential phase is required to ensure that population in a robust stage of growth and not in saturation mode. To disinfect the bacteria in robust stage is rather important than "stationary phase" of bacteria, as in the exponential stage, bacterial population is doubling constantly consequently increasing population count of bacteria. However, being in the exponential phase, it is rather difficult to get the same initial concentration.

The essential elements of the set-up include water storage tank, high pressure pump, different cavitating reactors such as orifice and vortex diode and control mechanism for parameters such as temperature, pressure, flowrate and so on. The photograph of the set-up is shown in Fig. 1. The details of experimental set-up are described in our earlier publications (Suryawanshi et al., 2016; Suryawanshi et al., 2017a; Suryawanshi et al., 2017b) therefore have not been repeated 
here for the sake of brevity. The following two different cavitating reactors were used in this work:

(a) Orifice: The orifice used in this study was having a single hole, diameter of $3 \mathrm{~mm}$, similar to that reported earlier (Suryawanshi et al., 2017a; Suryawanshi et al., 2017b). Acceleration of axial flow at the orifice leads to a low pressure region where cavitation occurs.

(b) Vortex based cavitation device (66 $\mathrm{mm}$ chamber diameter): Unlike orifice based cavitation reactor, rotational flow is used in this device to generate low pressure regions and cavitation.

The generated cavities are transported in high pressure region where they collapse. Collapsing cavities generate extreme conditions of collapse (T 10,000 K, P 1000 atm) and very high shear (Ranade and Bhandari, 2014; Saharan et al., 2014; Suryawanshi et al., 2016; Suryawanshi et al., 2017a; Suryawanshi et al., 2017b). The localised high temperature and pressure result in homolytic water cleaving to generate, in situ, oxidising species such as hydroxyl radicals or hydrogen peroxide. Oxidation in the presence of these powerful oxidising agents results in the removal/destruction of microorganisms, without actually employing any external chemicals or reagents. Very high shear generated during the cavity collapse may also physically break open the outer shell of microbes and therefore cause disinfection (Sawant et al., 2008).

A schematic of different flow patterns in the two cavitating devices, cavitation process and possible disinfection mechanism due to cavitation is shown in Fig. 1. For disinfection experiments, typically 12-20 L volume of effluent was used. Temperature was controlled using JULABO Chilling system (Model FL 1701, 20 L). Two different reactors mentioned above were used for the present study. Before carrying out disinfection experiments, efforts were made to identify flow rates (and corresponding pressure drops) at which cavitation inception occurs, i.e. from the deviation of pressure drop from the usual square law ( $\Delta \mathrm{P}$ proportional to square of flow rate or mean velocity) specific to cavitating device. Naturally, the point of cavitation inception varies from device to device and within the same category such as orifice, it can vary according to the engineering design. The cavitation inception was found to occur in the pressure drop range of 30 to $50 \mathrm{kPa}$ and 125 to $180 \mathrm{kPa}$ ( 0.3 to $0.5 \mathrm{bar}$ and 1.25 to $1.8 \mathrm{bar}$ ) for vortex diode and orifice respectively. Considering the inception points, the disinfection experiments were carried out at a pressure drop across vortex diode at 0.5, 1.0 and 2.0 and for orifice at 2 bar and above (2, 5 and 10). After setting the desired flow through the cavitation reactor, samples $(10 \mathrm{~mL})$ were withdrawn at regular intervals. For each sample, colony forming units (CFU) were determined as discussed in the following section. The reproducibility of the experiments was checked and was found satisfactory (within $\pm 6 \%$ for most experiments). 


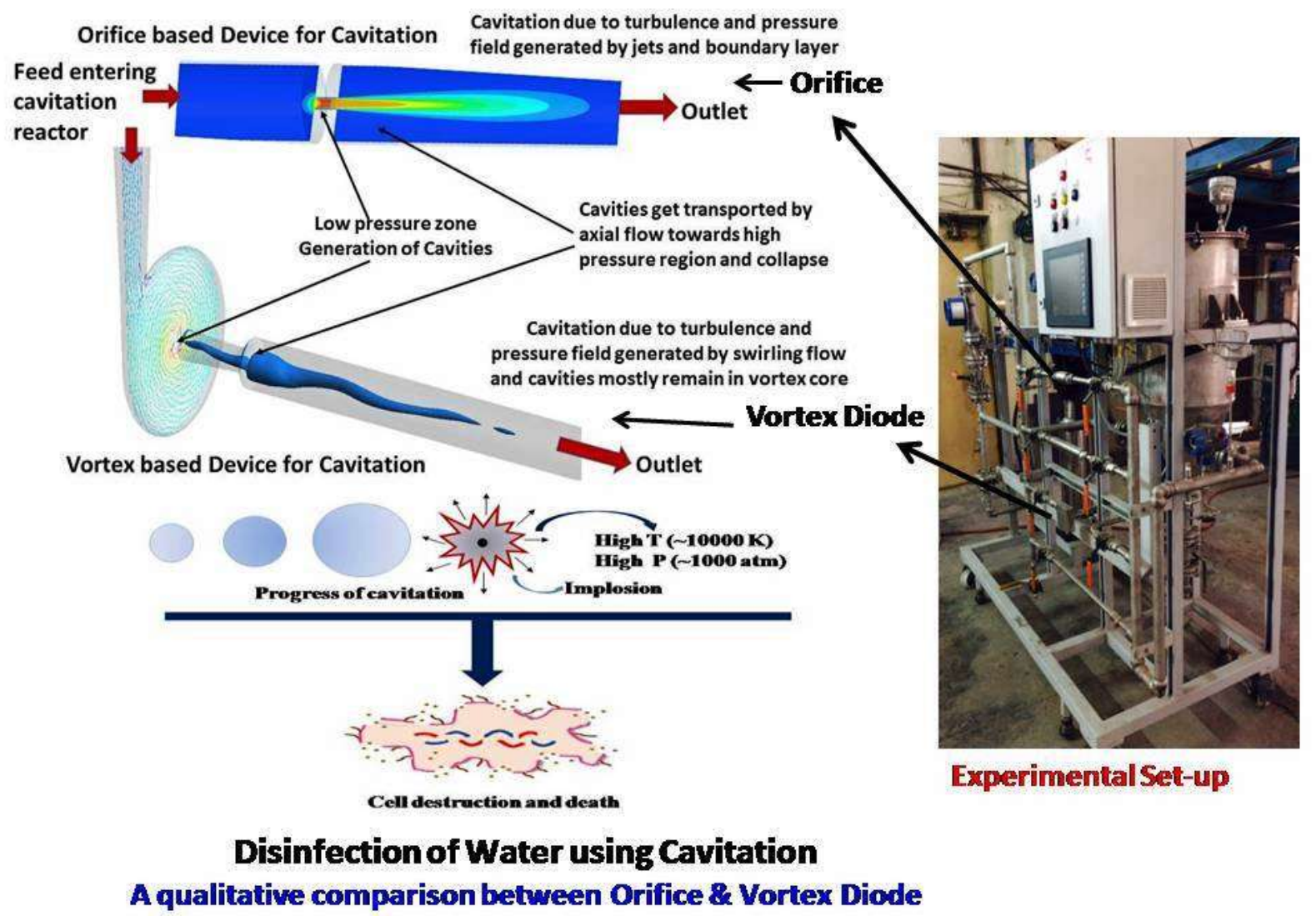

Fig. 1. Experimental Set-up and Schematic of disinfection using cavitation

\subsection{Disinfection activity}

Enumeration of viable bacteria present in model/contaminated water was done by plate count method. A volume $(0.1 \mathrm{ml})$ of each diluted solution was spread on $90 \mathrm{~mm}$ sterile nutrient agar plate. The spreading of sample was carried out under the laminar air flow to avoid contamination. Further all the inoculated plates were incubated at $37^{\circ} \mathrm{C}$ for $24 \mathrm{~h}$, the colonies of survived bacteria on agar plate were counted and presented as colony forming unit per milliliter (CFU/ml).

Colony Forming Unit was calculated using the equation,

$$
C F U / m l=\frac{\text { number of colonies on agar plate }}{\text { volume spreaded }} \times \text { dilution factor }
$$




\subsection{Isolation of bacteria}

$1 \mathrm{ml}$ of contaminated water sample was serially diluted using sterile distilled water. The dilutions were seeded on nutrient agar plates and were incubated at room temperature as the reactors are operational in room temperature. The colony showed distinct morphological and cultural characteristics were selected. Selected colonies were further streaked on the nutrient agar plates to get the pure colonies.

\subsection{Identification of bacterial isolates}

Genomic DNA was isolated from all the selected bacterial cultures by cell lysis protocol (Balapure et al., 2014). 16S r-RNA gene was amplified by PCR using $16 \mathrm{~S}$ universal primer (27F and 1492R) (Balapure et al., 2014). PCR amplification was conducted in an automated thermal cycler (BIO RAD PCR System) using the standard protocol. The amplified $1.5 \mathrm{~kb}$ PCR products were sequenced by DNA analyzer ( 3500 XL Genetic Analyzer, Applied Biosystems). The sequences were matched with BLASTn search using standalone blast against NCBI 16S r-RNA database to identify the closed bacterial strain to the query sequence. 16S r-RNA gene sequences were aligned and phylogenetic tree was constructed in maximum-likelihood method using the MEGA 6.0 (Kim et al., 2012).

\section{Results and Discussion}

\subsection{Disinfection of bacterial strains by vortex diode}

Fig. 2 shows the results of disinfection using vortex diode for gram- negative bacteria- E. coli. Efficient elimination of E.coli was achieved within $1 \mathrm{~h}$ of cavitation even at lower pressures and $99 \%$ of decontamination was achieved in 1 h of cavitation when pressure drop $(\Delta P)$ was as low as 0.5 bar. Further, increase in pressure drop up to 2 bar improves the removal and drastically reduces the time for disinfection. The increase in the pressure can positively impact time of operation (e.g. $\sim 50 \%$ ) as compared to that for low pressure and therefore the cost of operation.

Fig. 2 also shows the effect of pressure for vortex diode in the case of disinfection by eliminating gram--positive bacteria- $S$. aureus. It is evident that the elimination behavior in the case of gram- negative (E. coli) and gram- positive (S. aureus) bacteria is significantly different, especially at low pressure. As compared to $99 \%$ destruction observed for $E$. coli, the extent of destruction of $S$. aureus was only $61 \%$ at 0.5 bar pressure drop. However, the difference is practically indiscernible at higher pressures and close to $98 \%$ reduction was obtained using vortex diode at pressure drop values of 1 bar and 2 bar in $1 \mathrm{~h}$ operation. Again, similar to the 
observation for E. coli, the removal is better at higher pressures, indicating reduced time of operation. The photographs of petri dish showing reduction of $\mathrm{CFU} / \mathrm{mL}$ are provided as supplementary Fig. S1.
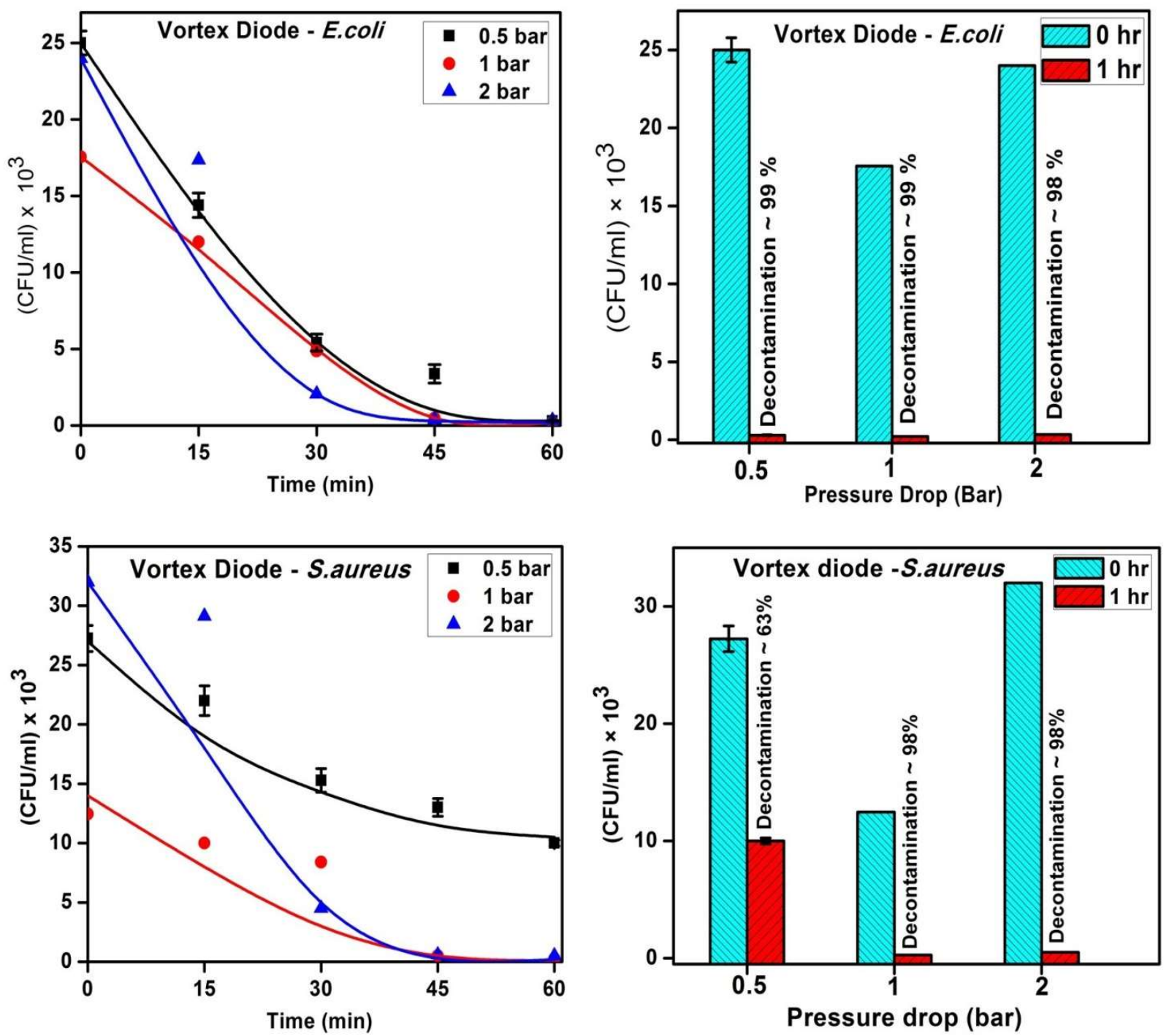

Fig.2. Effect of Pressure: Disinfection of E.coli and S. aureus by vortex diode

The discrepancy in the removal of two different types of bacteria, especially at low pressure in vortex diode, can be attributed to the difference in cell wall structure of microbes. The key mechanism responsible for destruction of bacteria under hydrodynamic cavitation is supposed 
to be mechanical disruption of the cell walls (Fig. 1). The cell wall of Gram-positive bacteria is composed of a thick layer of peptidoglycan and small amounts of teichoic acids. The peptidoglycan layer is much thinner in gram- negative bacteria compared to that of grampositive bacteria(Loraine et al., 2012; Mai-prochnow et al., 2016)' therefore it is expected to be less resistant to rupture of the cell wall through cavitation.

High inlet pressure and subsequent high pressure drop across the cavitating device can improve the quantity and quality of the cavities i.e. the number of cavities and size of cavitation bubbles. The comparatively large bubbles can cause efficient cavitation when they collapse. However, if the increase in the number of cavities goes to the extent where they escape from the liquid without collapse or suffer from incomplete collapse, it reduces the possibility of generation of extreme conditions- high pressure, high temperature, consequently decreasing production of hydroxyl radicals leading to reduced disinfection efficiency (Guo, 2016). In the present study, the disinfection efficiency was observed to remain stable up to 2 bar pressure drop, which shows the efficacy of vortex diode to eliminate pathogenic strain.

\subsection{Disinfection of bacterial strains by orifice}

The results of disinfection by orifice in the case of $E$. coli and S. aureus are given in Fig. 3. Since the inception of cavitation for orifice was higher than vortex diode (1.25 bar as compared to 0.3-0.5 bar pressure drop in vortex diode), the experiments were carried out at three different pressure drop conditions of 2 bar, 5 bar and 10 bar. Again, a very high extent of removal was seen using orifice as a cavitating device and similar to the vortex diode, the rate of destruction is higher at higher pressures. It was observed that close to $99 \%$ removal can be obtained even by using orifice for $E$. coli, though at higher pressures compared to vortex diode.

The results on the destruction of $S$. aureus have similar trend as that in vortex diode- less reduction of $\sim 68 \%$ at pressure drop of 2 bar, $~ 88 \%$ reduction at 5 bar and $98 \%$ reduction at 10 bar. The results for growth of bacteria on $\mathrm{N}$. agar plates before and after the treatment with orifice are provided in supplementary Fig. S2. It is evident that $98 \%$ of S. aureus disinfection was achieved only at pressure drop of 10 bar. 

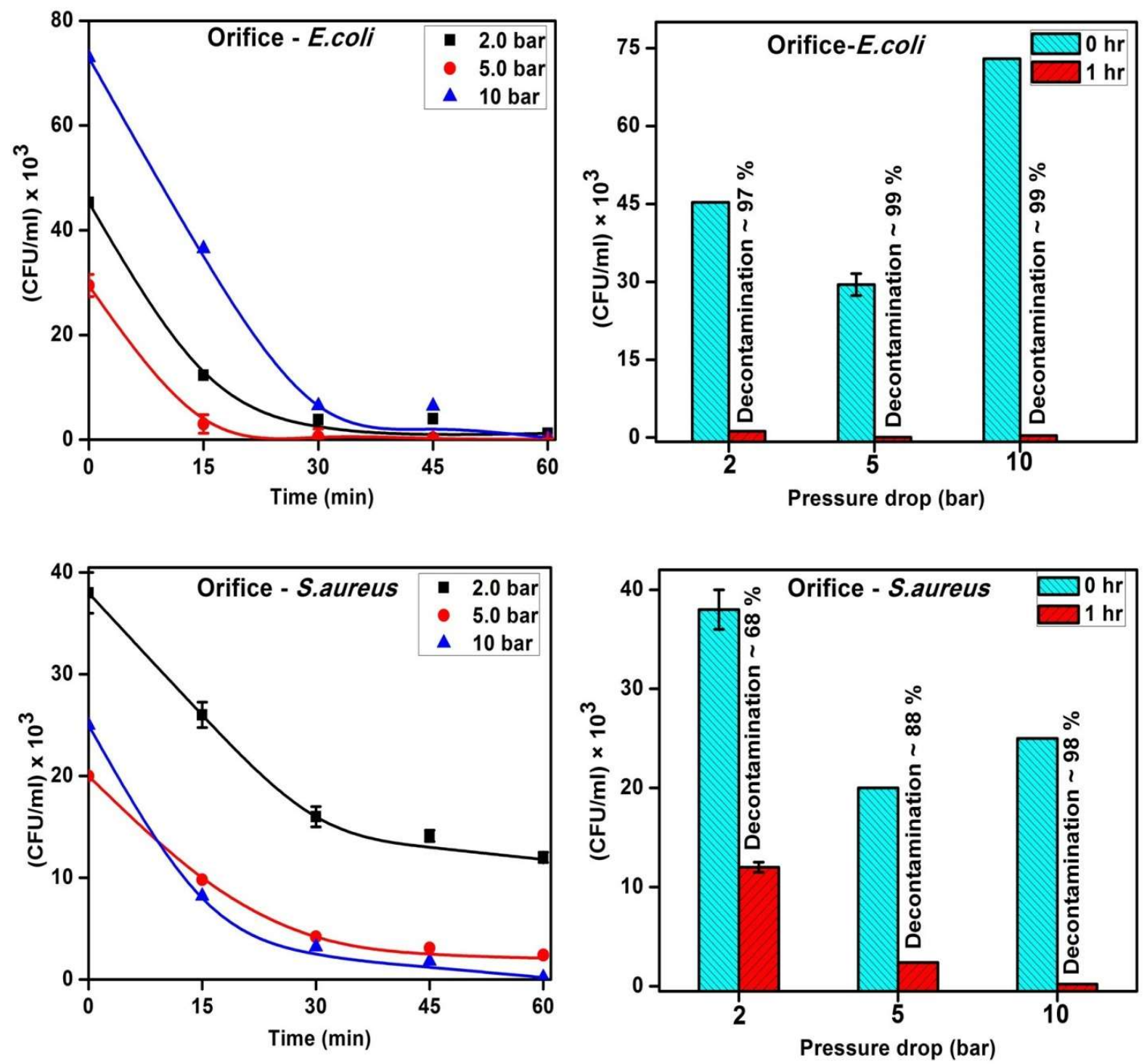

Fig.3. Effect of pressure: Disinfection of E. coli and S. aureus by orifice

\subsection{Disinfection efficiency for lower CFU values and for different reactor geometries}

In some of the previous reports, it was suggested that lower initial CFU count has significantly lowered efficiency as compared to higher concentration (Jyoti and Pandit, 2001; Jyoti and Pandit 2004a). The initial concentration of bacteria will impact cavitation. There are several possibilities such as, when the bacterial population (CFU/ml) is very low, the probability of a cavity collapse in the vicinity of a microorganism is also low while when the $\mathrm{CFU} / \mathrm{ml}$ is very high, then the number of cavities generated may not be sufficient to kill all the microorganisms. In the present work, to prove the concept, different concentrations of bacteria were used in the range $0.18 \times 10^{3}$ to $70 \times 10^{3} \mathrm{CFU} / \mathrm{ml}$. In order to evaluate and to validate low concentration 
effect, experiments were carried out at significantly lower CFU $\left(0.18\right.$ to $\left.4.5 \times 10^{3}\right)$ for three arbitrary combinations e.g. Orifice- $E$. coli, Orifice- $S$. aureus at 2, 5 and 10 pressure drop respectively. The results are shown in Fig. 4. It is evident that the low initial CFU count has practically no effect on the efficiency and a very high destruction similar to high initial CFU (Fig. 3) was obtained. Thus, the present study clearly confirms efficacy of the hydrodynamic cavitation technique at all concentrations of bacteria.
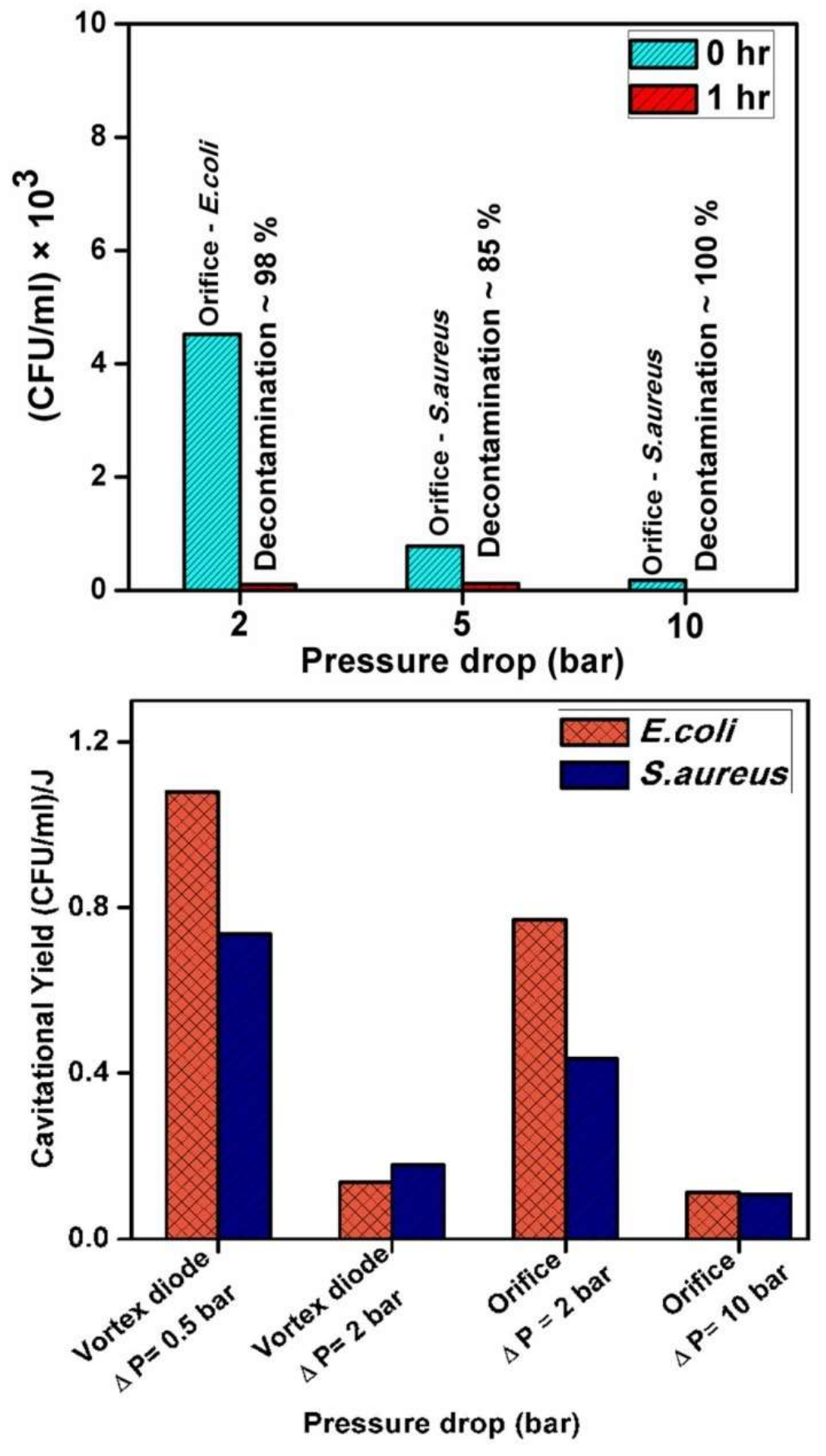

Fig 4. Effect of low initial CFU and cavitational yield comparison of vortex diode and orifice 
The differences in the results of vortex diode and orifice are naturally due to the different flow patterns produced in the two cavitating devices. It is not easy and straightforward to estimate the cavitation number in the case of vortex flow observed in vortex diode as compared to the conventional estimation in the case of linear flow of orifice. It is more useful to estimate the cavitational yield in the different configurations for comparing the performances of different devices. It is also important to note that the cavitation number cannot be used as a single parameter and large inconsistencies were reported, especially with different geometries (Šarc et al., 2017). The pressure at which the cavities collapse and the performance of the reactor varies from reactor to reactor because of the disparity in geometric configuration of the cavitating device (Guo, 2016). Sarvothaman et al. (2018) suggested that vortex device can shield the cavities from wall of the reactor and can overcome the limitations observed by conventional hydrodynamic cavitation devices. Thus, the higher efficiency and lower pressure drop for disinfection in vortex diode can be attributed to the vortex flow that possibly leads to increased number of cavities, improved quality of cavities along with cavity collapse as compared to the conventional device such as orifice.

Hydrodynamic cavitation for disinfection is not a new technique and many researchers have used it in the past, however with limited success. Further, the cavitating devices were rather of simple design such as ball valve (Jyoti and Pandit, 2001), rotor, driven by a simple milling cutter (Mezule et al., 2009) or orifice, cylindrical venturi and rectangular slit venturi and so on (Badve et al., 2015). As a consequence, disinfection efficiency was typically in the range of 44 to $75 \%$ under different operating conditions. Also, no systematic studies were reported on effect of various parameters for different bacteria. In the present study, vortex diode is clearly seen as more efficient in terms of achieving high reduction for both S. aureus and E. coli ( 98\% disinfection). The results are also significant due to the fact that, in drinking water treatment there should be complete elimination of bacteria (Gogate, 2007). In the case of orifice, significantly higher pressure drop conditions are required as compared to vortex diode, especially for eliminating gram- positive bacteria which implies high operational cost. For example, the initial load used in this work is in the range $0.18-70 \times 10^{3} \mathrm{CFU} / \mathrm{mL}$, while Jyoti and Pandit, (2001) used Initial load of $6.98 \times 10^{3} \mathrm{CFU} / \mathrm{mL}$ and found $22 \%$ disinfection at 1.72 bar pressure drop. Loraine et al. (2012) used initial concentration of $\sim 10^{7} \mathrm{CFU} / \mathrm{ml}$ of P.aeruginosa and observed 2 log reduction using orifice as a cavitating device with 16.5 bar pressure. The values of cavitational yield (Fig. 4) also indicate superiority of vortex diode in disinfection. 


\subsection{Cavitation model for kinetics of disinfection}

The schematic of disinfection set-up used in this work is shown in Fig. 5a.

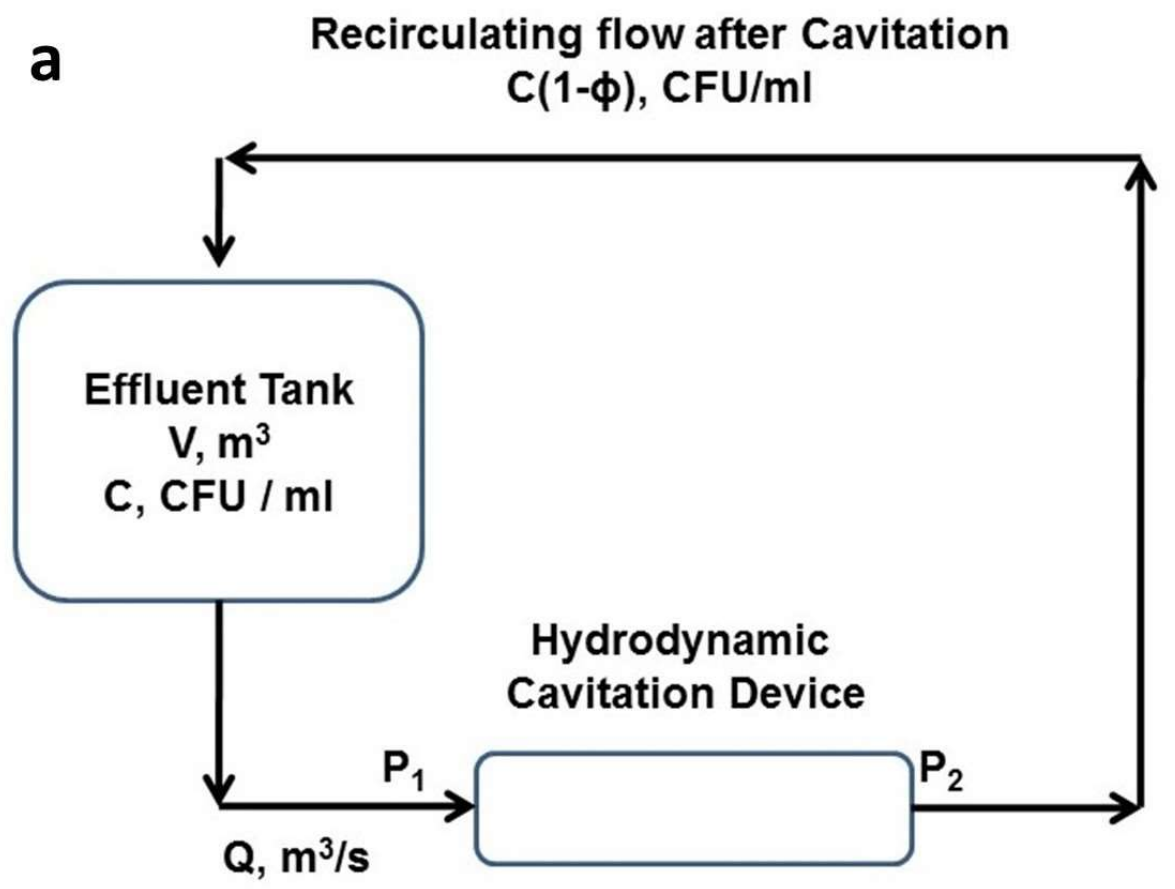

b

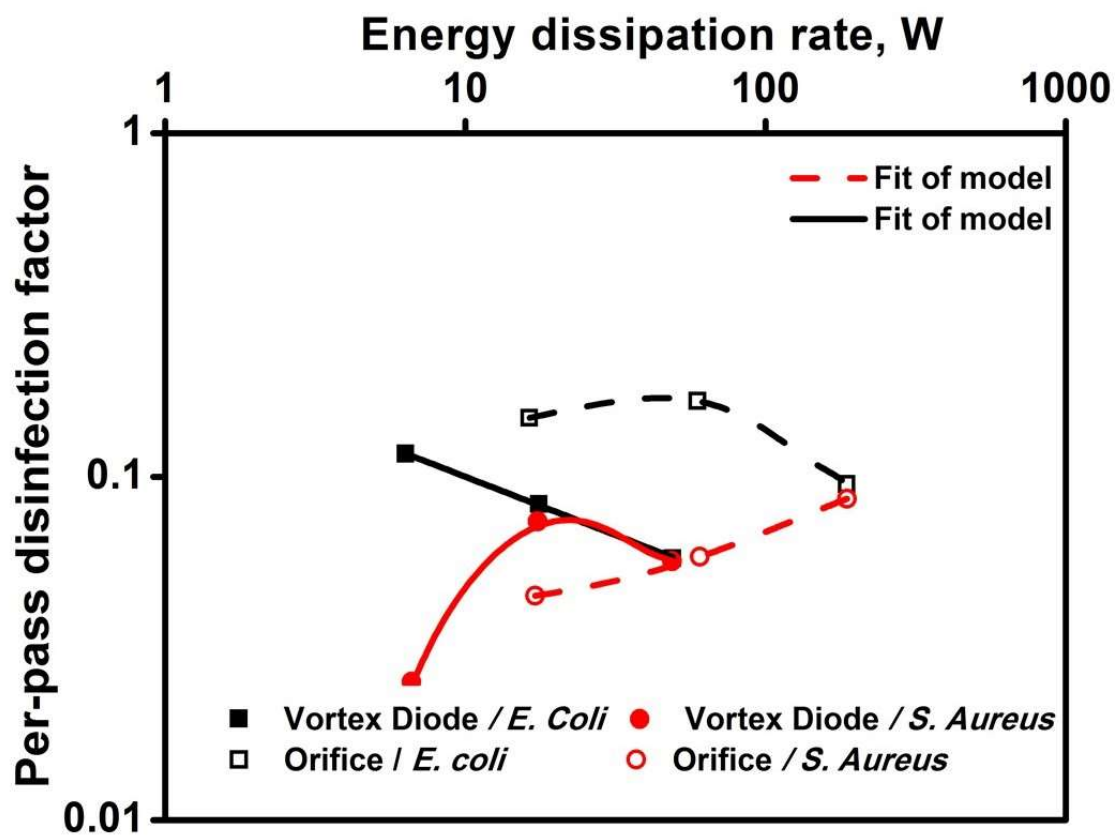

Fig. 5. (a) Schematic of water disinfection using hydrodynamic cavitation

(b) Per-pass degradation factors for two cavitation reactors 
The overall behaviour of a typical cavitation based disinfection set-up shown in Figure 1 and schematic of Fig.5a can be modelled in two ways. Most of the published papers have modelled the disinfection as a pseudo-first order kinetics as:

$V \frac{d C}{d t}=V\left(k_{G}-k\right) C$

Where $\mathrm{C}$ is concentration of microbes in the holding tank, $\mathrm{k}_{\mathrm{G}}$ is growth rate of microbes, $\mathrm{k}$ is disinfection rate of microbes and $\mathrm{V}$ is volume of holding tank. If growth and disinfection rates are not varying with time, the concentration may be written as:

$C=C_{i n} e^{-\left(k-k_{G}\right) t}$

It should however be noted that in reality disinfection is occurring because of cavitation and it therefore depends on number of passes through cavitation device rather than elapsed time, $t$ (Sarvothaman et al., 2018). The more appropriate description of the disinfection process is based on per-pass disinfection as:

$V \frac{d C}{d t}=V k_{G} C-Q \emptyset C$

Where $Q$ is flow rate through cavitation device and $\phi$ is per-pass disinfection occurring in cavitation device. The number of passes, $\mathrm{n}$ can be related to time as:

$n=\frac{Q}{V} t$

If the value of $\phi$ and $k_{G}$ are assumed to be constant over a range of concentration and time, one may write concentration of microbes at time $t$ as:

$C=C_{i n} e^{-\left(\varnothing-k_{G} \tau\right) n}$

Where $\tau$ is residence time in the holding tank (V/Q).

The growth rate can be related to doubling time, $t_{D}$ as:

$k_{G}=\frac{\ln }{t_{D}}$ 
If for the time scales of experiments, growth is not significant and therefore $k_{G} \tau$ is very small compared to per-pass disinfection $\phi$, (or $\mathrm{k}_{\mathrm{G}} \ll k$ ) the observed disinfection can be described as:

$C=C_{i n} e^{-k t}=C_{i n} e^{-\emptyset n}$

Thus, effective disinfection rate constant may be related to effective per-pass disinfection factor as:

$k=\frac{\emptyset n}{t}=\frac{\emptyset}{\tau}$

Thus, the apparent disinfection rate constant used by most of the studies on hydrodynamic cavitation is dependent on the residence time of the holding tank!

The residence time of $100 \mathrm{~s}$ and per-pass disinfection factor of 0.1 gives $\mathrm{k}$ as $0.001 \mathrm{~s}^{-1}$. This is included here so as to facilitate comparison of the reported per-pass disinfection factor with the values of effective disinfection rate constants reported in earlier studies. In this work, we prefer to report per-pass disinfection factor since it has a sound physical basis than reporting effective disinfection rate constant.

Once we obtain per-pass disinfection factor for a cavitation device, the overall cavitation yield, $\mathrm{CFU} / \mathrm{J}$ can be obtained as:

$Y=\frac{V\left(C_{i n}-C\right)}{\Delta P Q t} C F U / J$

For small values of $\phi$, it may be approximated as:

$Y=\left(\frac{\varnothing C}{\Delta P}\right) \quad C F U / J$

One may also calculate average disinfection rate over time ' $t_{\mathrm{op}}$ ' as:

$R_{\text {avg }}=\frac{C_{\text {in }}\left(1-e^{-k t}\right)}{t_{o p}}=\frac{C_{i n}\left(1-e^{-\emptyset n}\right)}{t_{o p}} \frac{C F U}{m l} / \mathrm{s}$

The values of $Q, V, t$ and concentration are known from the experiments. The experimental data of concentration as a function of number of passes through cavitation device was used to calculate per-pass disinfection factor $\phi$, using Eq. 7 and standard regression methods. The effective disinfection rate averaged over operation time was calculated simply using the Eq. 11 . The results of kinetics study using the cavitation model (Eq. 11) are presented in Table 1. 
Table 1: Rate of disinfection of $E$. coli and S. aureus in orifice and vortex diode

\begin{tabular}{|c|c|c|c|c|c|c|}
\hline Device & Microorganism & $\begin{array}{l}\text { Pressure } \\
\text { drop, } \\
\text { bar }\end{array}$ & $\begin{array}{l}\text { Initial } \\
\text { CFU/ml }\end{array}$ & $\begin{array}{l}\text { Final } \\
\text { CFU/mL }\end{array}$ & $\begin{array}{l}\text { Per-pass } \\
\text { disinfection } \\
\text { factor, } \phi\end{array}$ & $\begin{array}{l}\text { Disinfection Rate } \\
\text { (averaged over } \\
60 \mathrm{~min} \text { ), CFU/ml.s }\end{array}$ \\
\hline \multirow[t]{6}{*}{$\begin{array}{l}\text { Vortex } \\
\text { Diode }\end{array}$} & \multirow[t]{3}{*}{ E.coli } & 0.5 & 25000 & 300 & 0.12 & 6.9 \\
\hline & & 1 & 17560 & 220 & 0.085 & 4.8 \\
\hline & & 2 & 24000 & 340 & 0.06 & 6.6 \\
\hline & \multirow[t]{3}{*}{ S.aureus } & 0.5 & 27240 & 10000 & 0.025 & 4.8 \\
\hline & & 1 & 12460 & 260 & 0.075 & 3.4 \\
\hline & & 2 & 32000 & 500 & 0.06 & 8.75 \\
\hline \multirow[t]{6}{*}{ Orifice } & \multirow[t]{3}{*}{ E.coli } & 2 & 45300 & 1200 & 0.15 & 12.3 \\
\hline & & 5 & 29440 & 80 & 0.17 & 8.2 \\
\hline & & 10 & 72960 & 360 & 0.095 & 20.2 \\
\hline & \multirow{3}{*}{ S.aureus } & 2 & 38000 & 12000 & 0.045 & 7.2 \\
\hline & & 5 & 20000 & 2400 & 0.06 & 4.9 \\
\hline & & 10 & 25000 & 200 & 0.09 & 6.9 \\
\hline
\end{tabular}

It is evident that the value of rate of disinfection is very high, indicating effectiveness of cavitation, especially that using vortex diode. For orifice as a cavitating device, the similar rate of disinfection can be obtained at substantially higher pressures thereby at higher cost of operation. For disinfection of bore well water, Jyoti and Pandit, (2004a) reported disinfection rate values of the order of $0.00592 \mathrm{CFU} / \mathrm{ml}$.s for fecal streptococci and $0.01 \mathrm{CFU} / \mathrm{ml}$.s for total coliform using hybrid techniques of hydrodynamic cavitation coupled with ozone, which is significantly lower than that obtained in this work. The reported values for intensified processes such as acoustic cavitation coupled with ozone were also substantially lower. It is to be noted that the rate of disinfection would vary with the method and also with the nature of the cavitating device (in the case of hydrodynamic cavitation). Jyoti and Pandit, (2004b) observed large differences in the rates of disinfection in ultrasonic bath compared to ultrasonic horn, which was attributed to uniformity of cavities distribution in ultrasonic bath and intense, but restricted cavitation effect on the tip of the horn. As compared to the various techniques reported in the literature, in isolation or in hybrid form (e.g. hydrogen peroxide treatment, ozone, ultrasonic cavitation and hybrid processes) the present work clearly highlights a more uniform and intense cavitation effects in disinfection, high efficiency and also ease of operation compared to ultrasonic cavitation. Further, the results corroborate the previous findings (Jyoti and Pandit, 2001) that when the water is more polluted (high, initial CFU/ml) and larger volumes are to be treated, hydrodynamic cavitation gives excellent performance. Unlike their 
report, the present study indicated excellent disinfection efficiency of more than $95 \%$ even at low CFU. Thus, our study clearly points out the suitability of the disinfection technique, irrespective of the nature and number of the bacteria.

In the literature, very few studies have attempted to relate the overall disinfection rate to perpass disinfection. Most of the studies use apparent first order kinetics and report the effective rate constant of disinfection. However, this effective disinfection rate constant is a function of residence time and is not directly related to the performance of a cavitation reactor. Therefore, in this work, we prefer to interpret the experimental data using the per-pass disinfection parameter.

If growth of microbes under operating condition is ignored, the effective per - pass disinfection factor is same as actual per - pass disinfection factor. The finite growth rate will increase actual per - pass disinfection factor. Considering the time scales of experiments, we have decided to ignore influence of finite growth rate following the prevalent practice in the literature. The perpass degradation factors for the two microbes investigated in this work with two cavitation reactors are shown in Fig. $5 b$ as a function of energy dissipation rate.

It can be seen that per-pass disinfection factors for $E$. coli are higher than $S$. aureus for a given cavitation device. It is worthy to note that vortex diode offers similar per - pass disinfection performance to orifice at much lower energy consumption. The difference in the per-pass disinfection factors for $E$. coli and S. aureus decreases as energy dissipation rate increases for both the cavitation devices. This difference in per-pass disinfection is because of different cell wall strengths of E. coli and S. aureus. Sawant et al., (2008) have attempted to relate the cell wall strengths and per-pass degradation factors for orifice. No such attempt is made here because of the lack of detailed data on flow structure in vortex diodes. Recently Sarvothaman et al., (2018) have taken first steps towards developing a multi-layer model to simulate per pass performance of vortex diodes. These models may be extended later to describe disinfection behaviour observed in this case.

\subsection{Mechanism of water disinfection using hydrodynamic cavitation}

Disinfection process demands nearly complete removal or destruction of the bacterial cells and during destruction, the cell death may occur due to various physical and chemical mechanisms. Oxidation is a commonly used process for disinfection and use of oxidants such as hydrogen peroxide has been known for long time. Yoshpe-Purer and Eylan, (1968) reported disinfection using hydrogen peroxide for removal of $E$. coli and S. aureus as a slow process that requires 
presence of catalyst such as $\mathrm{Fe}^{2+}$ or $\mathrm{Cu}^{2+}$ to improve the rate. Though the exact mechanism was not clear, the role of hydroxyl radicals was considered to be most important. According to EPA water treatment manual on disinfection (EPA, 2012), the use of hydrogen peroxide in the treatment of potable water has been very limited due to its instability in storage and though it is a strong oxidising agent, it is considered as a poor disinfectant achieving little inactivation of bacteria and viruses. These observations certainly discourage and would limit its applicability, especially in wastewater treatment disinfection applications where other contaminants are largely present.

The exact mechanism of destruction of microorganisms leading to water disinfection using hydrodynamic cavitation has not been conclusively established (Gogate, 2007). The hydrodynamic cavitation process is one variant of advanced oxidation process that has the capacity to generate in situ hydroxyl radicals and hydrogen peroxide (Saharan et al., 2014). The cavitation effect is believed to rupture the chemical bonds between the molecular components of cell membranes leading to increased permeability of $\mathrm{H}_{2} \mathrm{O}_{2}$ (Dahi, 1967). The cavitation also possibly makes individual cells susceptible for cell destruction (Burleson et al., 1975). Further, for increasing efficacy different process combinations such as cavitation and $\mathrm{H}_{2} \mathrm{O}_{2}$, cavitation and ozone are possible (Jyoti and Pandit, 2004a; Jyoti and Pandit, 2004b). Many a times, improved results have been obtained using process integration or such process intensification.

In the present work, since there are no chemicals used, it is postulated that the destruction of microorganism occurs due to shear, oxidation and heat effects. This is schematically shown in Fig. 6 where the strong oxidizing agents such as hydroxyl radicals generated during the cavitation result into oxidative damage to the cells due to protein oxidation or DNA damage; oxidation of lipoproteins, glycooxidation, and oxidation of DNA subsequently causing cell death as reported by several researchers (Bandyopadhyay et al., 1999, Phaniendra and Babu, 2015). Localized heating and intense shear generated by cavity implosion also result into cell death. The rate of cell destruction is believed to be dependent upon number of factors such as number and density of the cavities, concentration of the microbes, reactor geometry, pressure drop, presence of other pollutants, presence of suspended solids and so on. The nature of the microorganism is also important as can be seen from the large difference in disinfection obtained for E. coli and S. aureus. The prediction of generation of hydroxyl radicals using computation fluid dynamics coupled with cell death can possibly provide order of magnitude description and incorporating all the parameters impacting cavitation and/or cell death appears to be extremely complex and difficult. 


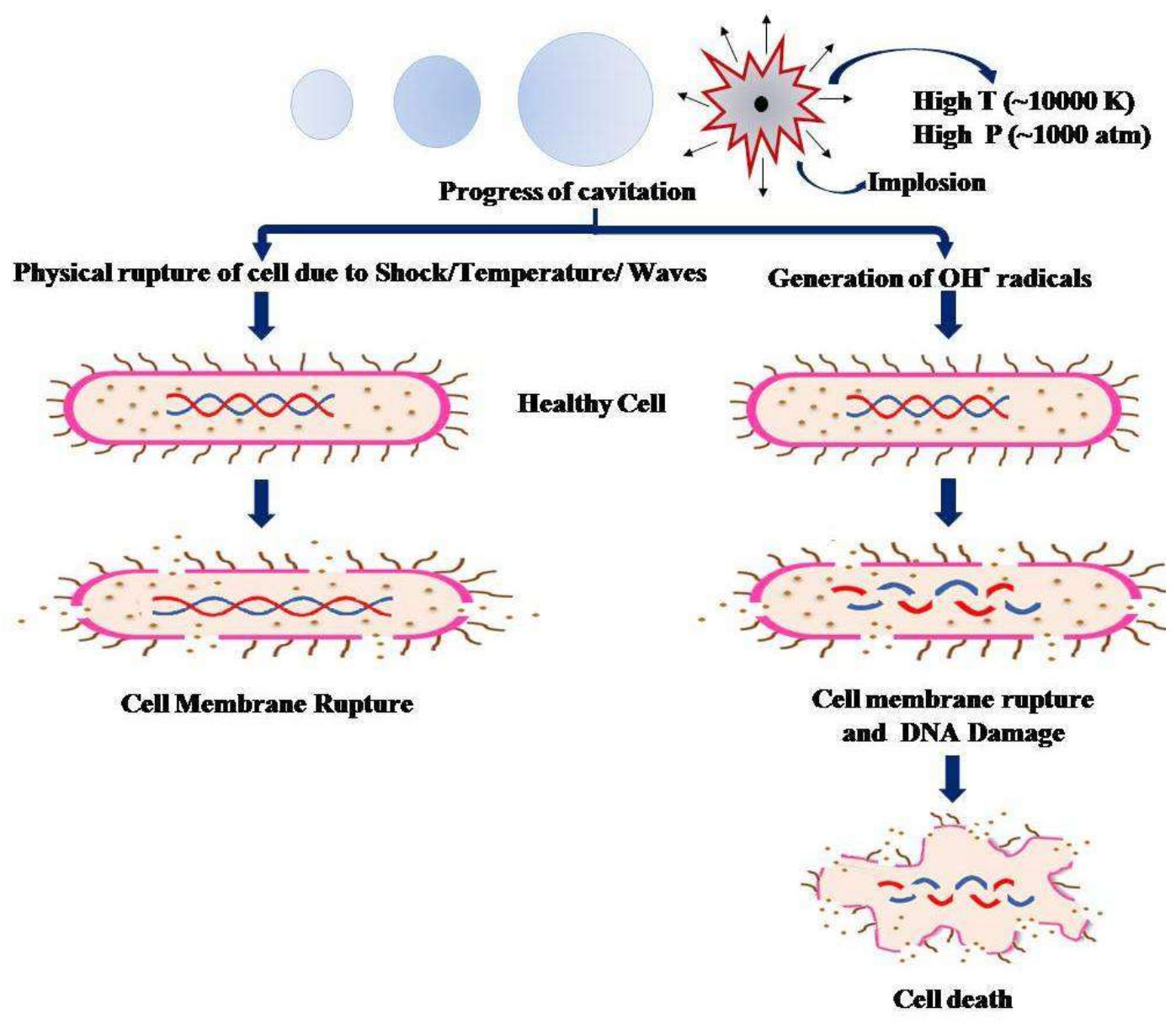

Fig. 6. Plausible mechanism of disinfection through cell destruction by hydrodynamic cavitation

\subsection{Treatment of contaminated raw water containing mixture of microorganisms}

In addition to pathogens, raw water from various sources can contain other contaminants including organic pollutants that may interfere with the disinfection process or limit the application of the treatment process. In this regard, hydrodynamic cavitation can prove to be highly useful technology as it can also destroy/ mineralize other organic contaminants apart from eliminating other microorganisms. To provide proof of concept in this regard, a water stream with mixture of microorganisms was used for hydrodynamic cavitation studies.

16Sr-RNA gene analysis revealed that contaminated raw water contain 5 bacterial species namely Staphylococcus aureus strain BJ1 (MH891759), Staphylococcus aureus strain BJ2 (MH891760), Bacillus cereus strain BJ3 (MH891761), Stenotrophomonas maltophilia strain BJ4 
(MH891762), Staphylococcus aureus strain BJ5 (MH891763). The overall taxonomic and genetic relationship of all of the isolated bacterial cultures and their closely resembling species are shown in phylogenetic tree Supplementary Fig. S3. Phylogenetic tree depicts that all isolated species representing two different bacterial classes Bacilli and Gammaproteobacteria, which are reported as potential pathogens in contaminated water (Balcom et al., 2016). The decontamination of raw water containing mixture of microorganism was carried out using both vortex diode and orifice to validate the feasibility of the system to treat real wastewater.

The results with the contaminated water using hydrodynamic cavitation system revealed significant microbial reduction for both vortex diode and orifice, though lower than that obtained for single bacterial system. Disinfection efficiency for overall reduction was observed to be $56 \%$ and $44 \%$ for vortex diode ( 0.5 bar) and orifice ( 2 bar) respectively. The efficiency of the treatment may be increases further after optimizing different process parameters such as pressure drop, temperature and so on.

\section{Conclusions}

The hydrodynamic cavitation technology using vortex diode was found to be highly efficient technology for elimination of various microorganisms from the class of gram- negative and gram- positive bacteria. A very high removal (99\%) of E.coli was achieved within 1 h of cavitaion for vortex diode as a cavitating device at a very low pressure drop of only 0.5 bar. The destruction of $S$. aureus was lower at low pressure drop in comparison to the removal of gramnegative bacteria- $E$. coli which can be increased up to $98 \%$ by increasing the pressure drop. As compared to vortex diode, the conventional cavitating device-orifice, that employs linear flow for cavitation was found to require significantly higher pressure drop conditions for disinfection and eliminating gram- positive bacteria with high efficiency was possible only at a very high pressure drop up to 10 bar. A possible mechanism for disinfection was proposed that elucidates the role of cavitation in damage of the cells as well as oxidative effect leading to cell death due to DNA damage. A cavitation model using per pass disinfection was developed that can provide more meaningful physical description of the disinfection process as against the conventional first order rate model. The hydrodynamic cavitation using vortex diode clearly appears to be simple, easy to operate, accurate, effective and green technology for disinfection of water. The process is also easy to scale-up, thus, indicating its potential commercial applicability, at least as a primary method of treatment for disinfection, that can be subsequently combined with other conventional methods for complete disinfection. 


\section{Acknowledgement}

The project was funded by DST-WTI project (GAP 317526) of Department of Science and Technology, India. The co-authors, Dr. Balapure and Dr. Jena would like to acknowledge the financial support from Department of Science and Technology, India.

\section{References}

Alexandre, E.M.C., Brandão, T.R.S., Silva, C.L.M., 2013. Impact of non-thermal technologies and sanitizer solutions on microbial load reduction and quality factor retention of frozen red bell peppers. Innov. Food Sci. Emerg. Technol. 17, 99-105. https://doi.org/10.1016/J.IFSET.2012.11.009

Badve, M.P., Bhagat, M.N., Pandit, A.B., 2015. Microbial disinfection of seawater using hydrodynamic cavitation. Sep. Purif. Technol. 151, 31-38. https://doi.org/10.1016/j.seppur.2015.07.020

Balapure, K.H., Jain, K., Chattaraj, S., Bhatt, N.S., Madamwar, D., 2014. Co-metabolic degradation of diazo dye-Reactive blue 160 by enriched mixed cultures BDN. J. Hazard. Mater. 279, 85-95. https://doi.org/10.1016/j.jhazmat.2014.06.057

Balcom, I.N., Driscoll, H., Vincent, J., Leduc, M., 2016. Metagenomic analysis of an ecological wastewater treatment plant's microbial communities and their potential to metabolize pharmaceuticals. F1000 Research 5, 1881. https://doi.org/10.12688/f1000research.9157.1

Bandyopadhyay, U., Das, D., Banerjee, R.K., 1999. Reactive oxygen species : Oxidative damage and pathogenesis 77.

Bilek, S.E., Turantas, F., 2013. Decontamination efficiency of high power ultrasound in the fruit and vegetable industry, a review. FOOD Int. J. Food Microbiol. 166, 155-162.

Broekman, S., Pohlmann, O., Beardwood, E.S., de Meulenaer, E.C., 2010. Ultrasonic treatment for microbiological control of water systems. Ultrason. Sonochem. 17, 1041-1048. https://doi.org/10.1016/J.ULTSONCH.2009.11.011

Burleson, G.R., Murray, T.M., Pollard, M., 1975. Inactivation of viruses and bacteria by ozone, with and without sonication. Appl. Microbiol. 29, 340-344.

Čehovin, M., Medic, A., Scheideler, J., Mielcke, J., Ried, A., Kompare, B., Žgajnar Gotvajn, A., 2017. Hydrodynamic cavitation in combination with the ozone, hydrogen peroxide and the UV-based advanced oxidation processes for the removal of natural organic matter from drinking water. Ultrason. Sonochem. 37, 394-404. https://doi.org/10.1016/j.ultsonch.2017.01.036

Dahi, E., 1967. Physicochemical aspects of disinfection of water by means of ultrasound and ozone. Water Research 10 (8), 677.https://doi.org/10.1016/0043-1354(76)90005-1.

EPA, 2012. Hazardous Waste Listings. A User-Friendly Reference Document for Hazardous Waste

Listings. https://www.epa.gov/sites/production/files/201601/documents/hw_listref_sep2012.pdf.

Fogden, J., 2009. Access to safe drinking water and its impact on global economic growth. HaloSource, Inc. 76.

Gogate, P.R., 2007. Application of cavitational reactors for water disinfection: Current status 
and path forward. J. Environ. Manage. 85, 801-815. https://doi.org/10.1016/j.jenvman.2007.07. 001

Guo, Z., 2016. Application of Hydrodynamic Cavitation to Wastewater Treatment 1363-1376. https://doi.org/10.1002/ceat.201500362

Joyce, E., Mason, T.J., Phull, S.S., Lorimer, J.P., 2003. The development and evaluation of electrolysis in conjunction with power ultrasound for the disinfection of bacterial suspensions. Ultrason. Sonochem. 10, 231-234. https://doi.org/10.1016/S13504177(03)00109-3

Jyoti, K.K., Pandit, A.B., 2004a. Ozone and cavitation for water disinfection. Biochem. Eng. J. 18, 9-19. https://doi.org/10.1016/S1369-703X(03)00116-5

Jyoti, K.K., Pandit, A.B., 2004b. Effect of cavitation on chemical disinfection efficiency. Water Res. 38, 2248-2257. https://doi.org/10.1016/j.watres.2004.02.012

Jyoti, K.K., Pandit, A.B., 2001. Water disinfection by acoustic and hydrodynamic cavitation. Biochem. Eng. J. 7, 201-212. https://doi.org/10.1016/S1369-703X(00)00128-5

Karunakaran, C., Ganapathy, A., Paramasivan, G., Govindasamy, M., Viswanathan, A., 2011. $\mathrm{NiO} / \mathrm{TiO} 2$ nanoparticles for photocatalytic disinfection of bacteria under visible light. J. Am. Ceram. Soc. 94, 2499-2505. https://doi.org/10.1111/j.1551-2916.2011.04403.

Kim, O., Cho, Y., Lee, K., Yoon, S., Kim, M., Na, H., Park, S., Jeon, Y.S., Lee, J., Yi, H., Won, S., Chun, J., 2012. Introducing EzTaxon-e : a prokaryotic 16S rRNA gene sequence database with phylotypes that represent uncultured species. Int J Syst Evol Microbiol. 716-721. https://doi.org/10.1099/ijs.0.038075-0

Kirti, S., Bhandari, V.M., Jena, J., Sorokhaibam, L.G., Bhattacharyya, A.S., 2018a. Exploiting functionalities of biomass in nanocomposite development : application in dye removal and disinfection along with process intensification. Clean Technol. Environ. Policy 20, 981-994. https://doi.org/10.1007/s10098-018-1519-1

Kirti, S., Bhandari, V.M., Jena, J., Bhattacharyya, A.S., 2018b. Elucidating efficacy of biomass derived nanocomposites in water and wastewater treatment. J. Environ. Manage. 226, 95105. https://doi.org/10.1016/j.jenvman.2018.08.028

Liang, Y., Zhang, Z., Yang, X., Liu, W., 2013. Effect of suspended solids on the sequential disinfection of secondary effluent by UV irradiation and chlorination. J. Environ. Eng. 139, 1482-1487. https://doi.org/10.1061/(ASCE)EE.1943-7870.0000767

Loraine, G., Chahine, G., Hsiao, C.T., Choi, J.K., Aley, P., 2012. Disinfection of gram-negative and gram-positive bacteria using DynaJets ${ }^{\circledR}$ hydrodynamic cavitating jets. Ultrason. Sonochem. 19, 710-717. https://doi.org/10.1016/j.ultsonch.2011.10.011

Mai-prochnow, A., Clauson, M., Hong, J., Murphy, A.B., 2016. Gram positive and Gram negative bacteria differ in their sensitivity to cold plasma. Nat. Publ. Gr. 1-11. https://doi.org/10.1038/srep38610

Mezule, L., Tsyfansky, S., Yakushevich, V., Juhna, T., 2009. A simple technique for water disinfection with hydrodynamic cavitation: Effect on survival of Escherichia coli. Desalination 248, 152-159. https://doi.org/10.1016/j.desal.2008.05.051

Phaniendra, A., Babu, D., 2015. Free Radicals : Properties, Sources , Targets, and Their Implication in Various Diseases 30, 11-26. https://doi.org/10.1007/s12291-014-0446-0

Ranade, V.V., Bhandari, V.M., 2014. Industrial Wastewater Treatment, Recycling and Reuse. Butterworth-Heinemann, Oxford. DOI: 10.1016/B978-0-08-099968-5.00001-5 
Richardson, S.D., Plewa, M.J., Wagner, E.D., Schoeny, R., DeMarini, D.M., 2007. Occurrence, genotoxicity, and carcinogenicity of regulated and emerging disinfection by-products in drinking water: A review and roadmap for research. Mutat. Res. - Rev. Mutat. Res. 636, 178-242. https://doi.org/10.1016/j.mrrev.2007.09.001

Saharan V., Pinjari, D.V, Gogate, P.R., Pandit, Pandit. A., (2014). Chapter 3-Advanced Oxidation Technologies for wastewater Treatment: An Overview. Ind. Wastewater Treat. Recycl. Reuse 2014. p. 141-91. http://dx.doi.org/10.1016/B978-0-08-099968-5.00003-9

Šarc, A., Stepišnik-Perdih, T., Petkovšek, M., Dular, M., 2017. The issue of cavitation number value in studies of water treatment by hydrodynamic cavitation. Ultrason. Sonochem. 34, 51-59. https://doi.org/10.1016/j.ultsonch.2016.05.020

Sarvothaman, V.P., Simpson, A.T., Ranade, V.V., 2018. Modelling of vortex based hydrodynamic cavitation reactors. Chem. Eng. J. 0-1. https://doi.org/10.1016/j.cej.2018.08.025

Sawant, S.S., Anil, A.C., Krishnamurthy, V., Gaonkar, C., Kolwalkar, J., Khandeparker, L., Desai, D., Mahulkar, A.V., Ranade, V.V., Pandit, A.B., 2008. Effect of hydrodynamic cavitation on zooplankton: A tool for disinfection. Biochem. Eng. J. 42, 320-328. https://doi.org/10.1016/j.bej.2008.08.001

Suryawanshi, N.B., Bhandari, V.M., Sorokhaibam, L.G., Ranade, V. V., 2016. A Non-catalytic Deep Desulphurization Process using Hydrodynamic Cavitation. Sci. Rep. 6, 1-8. https://doi.org/10.1038/srep33021

Suryawanshi, N.B., Bhandari, V.M., Sorokhaibam, L.G., Ranade, V. V., 2017a. Developing technoeconomically sustainable methodologies for deep desulfurization using hydrodynamic cavitation. Fuel 210, 482-490. https://doi.org/10.1016/j.fuel.2017.08.106

Suryawanshi, P.G., Bhandari, V.M., Sorokhaibam, L.G., Ruparelia, J.P., Ranade, V. V., 2017b. Solvent degradation studies using hydrodynamic cavitation. Environ. Prog. Sustain. Energy 37. https://doi.org/10.1002/ep.12674

Villanueva, C.M., Cordier, S., Font-Ribera, L., Salas, L.A., Levallois, P., 2015. Overview of Disinfection By-products and Associated Health Effects. Curr. Environ. Heal. reports 2, 107-115. https://doi.org/10.1007/s40572-014-0032-x

Yoshpe-Purer, Y., Eylan, E., 1968. Disinfection of water by hydrogen peroxide. Health Lab. Sci. 5:233-238. https://doi.org/https://www.ncbi.nlm.nih.gov/pubmed/4880129

Zou, H., Wang, L., 2017. The disinfection effect of a novel continuous-flow water sterilizing system coupling dual-frequency ultrasound with sodium hypochlorite in pilot scale. Ultrason. Sonochem. 36, 246-252. https://doi.org/10.1016/j.ultsonch.2016.11.041 




E. coli

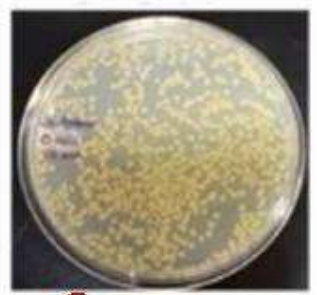

S. aureus



Feed<smiles>[Li][13CH3]</smiles>

Orifice based Device for Cavitation
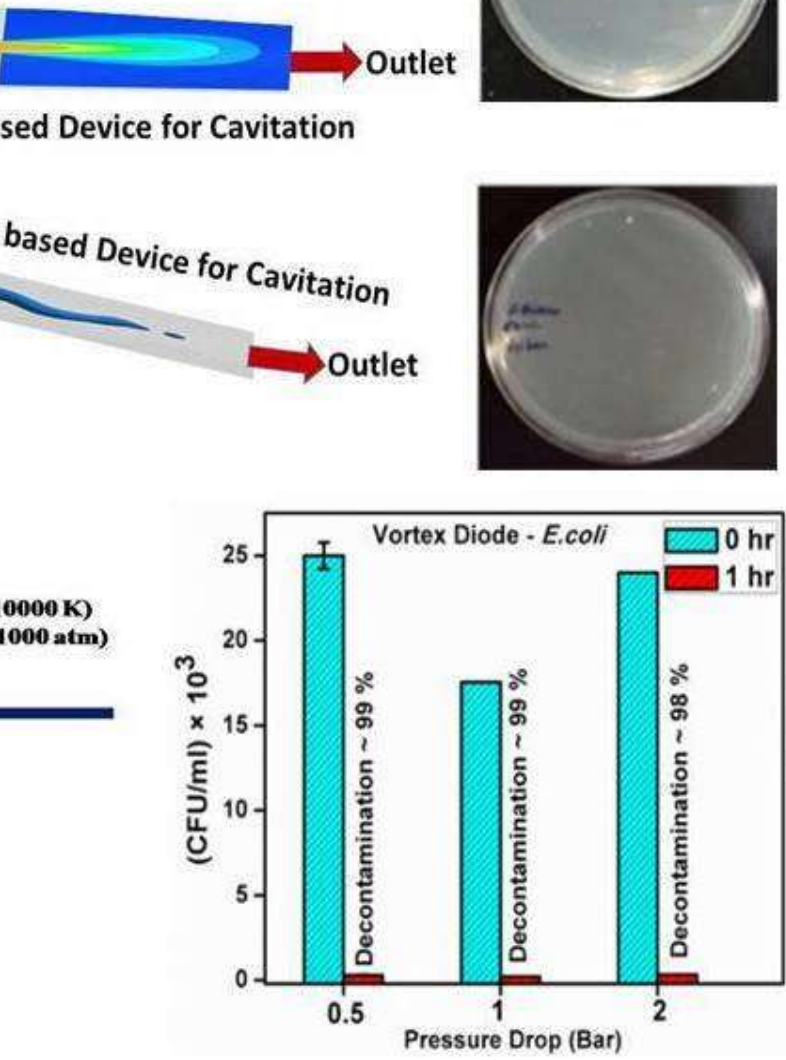